ARTICLE

https://doi.org/10.1038/s41467-018-07754-1

\title{
Blocking-cyclization technique for precise synthesis of cyclic polymers with regulated topology
}

Jie Chen ${ }^{1}$, Hongfei Li ${ }^{1}$, Hengchen Zhang ${ }^{1}$, Xiaojuan Liao ${ }^{1}$, Huijing Han¹, Lidong Zhang ${ }^{1}$, Ruyi Sun ${ }^{1}$ \& Meiran Xie ${ }^{1}$

Ring-closure and ring-expansion techniques are the two routes for extensive synthesis of cyclic polymers. Here, we report an alternative blocking-cyclization technique referred to as the third route to prepare cyclic polymers with regulated ring size and ring number by ringopening metathesis polymerization of di- and monofunctional monomers in a one-pot process, where the polymer intermediates bearing two single-stranded blocks are efficiently cyclized by the cyclizing unit of propagated ladderphane to generate corresponding mono-, bis-, and tricyclic polymers, and the well-defined ladderphane structure plays a crucial role in forming the cyclic topology. Monocyclic polymer is further modified via Alder-ene reaction and the cyclic molecular topology is clearly demonstrated. The diversity features of cyclic polymers are comprehensively revealed. This strategy has broken through the limitations of previous two cyclizing routes, and indeed opens a facile and popular way to various cyclic polymers by commercial Grubbs catalyst and conventional metathesis polymerization.

\footnotetext{
${ }^{1}$ School of Chemistry and Molecular Engineering, East China Normal University, Shanghai 200241, China. Correspondence and requests for materials should be addressed to R.S. (email: rysun@chem.ecnu.edu.cn) or to M.X. (email: mrxie@chem.ecnu.edu.cn)
} 
$\mathrm{n}$ the past decades, cyclic polymers have attracted a large academic attention because of their unique physical and solution properties intrinsic to their endless molecular topology ${ }^{1-4}$, including a more significant difference in the surface structure $^{5,6}$, smaller hydrodynamic volume ${ }^{7,8}$, lower viscosity 9,10 , and higher glass transition temperature ${ }^{11}$ in comparison to the usual linear analogues. Despite there have a large number of reports on the formation of cyclic polymers previously, the strict synthetic strategies were divided into only two categories: ring-closure technique and ring-expansion technique ${ }^{10,12,13}$. The ring-closure technique (Fig. 1a) is a traditional route, containing separated two steps of linear polymer precursor synthesis and its cyclization at extremely low concentration of $10^{-5} \mathrm{~mol} \mathrm{~L}^{-1} 6,12,14,15$. Initial synthetic pathway is the one way focused primarily on the bimolecular homodifunctional cyclization, due to the relative easy synthesis of homodifunctional polymer precursors. However, if one of the homodifunctional polymers is excess or insufficient, both end-groups of the identical polymer will react with another homodifunctional polymer to produce linear by-product and thus prevent cyclization. Even with 1:1 stoichiometry, excluding this reaction still be difficult because of the detailed competitive kinetics between intramolecular cyclization and intermolecular oligomerization ${ }^{12}$. In order to overcome the complication of bimolecular homodifunctional polymer cyclization, an alternative approach that the direct coupling reaction between two end-groups of unimolecular homodifunctional polymer precursor has been extended ${ }^{16,17}$. For example, the linear precursor with telechelic allyl end-groups was easily converted to macrocycle by a Grubbs catalyst-mediated ring-closing metathesis at extremely low concentration ${ }^{17}$. The other known way is the cyclization of unimolecular heterodifunctional polymer precursors bearing highly active functional groups at opposite chain ends by efficient coupling reaction at high dilution ${ }^{18,19}$, resulting in a high purity cyclic polymer. The most common one is the click cyclization of linear $\alpha, \omega$-heterodifunctional polymer precursor bearing azido and ethynyl groups to form the 1,4-disubstituted 1,2,3-triazole-connected cyclic polymer ${ }^{4,15,16,18,20}$. This method requires a very low molarity of reactive end groups for the cyclization reaction at high dilution, while it is still highly challenging to synthesize the well-defined cyclic polymers with large rings by this method, because the cyclization reaction of long linear precursors is thermodynamically disfavored, and the entropic penalty associated with localizing two end-groups of identical polymer chain into a region of required space for cyclization increases exponentially with the chain length. Instead of small functional groups at chainends, the cyclization of the $\mathrm{ABC}$ triblock copolymer precursors, composed of long central block B and two short blocks A and C bearing reactive antagonist functions under highly dilute conditions, is an alternative pathway to cyclic polymers ${ }^{5,6}$. In a word, the linear polymer precursor and highly diluted reaction condition are inevitably required in ring-closure technique, and the cyclization always occurs on the two reactive end groups of isolated polymer precursor without living species and must be triggered by the extra initiator.

Another synthetic route is ring-expansion technique (Fig. 1b), and the in situ cyclization invariably arises from the cyclic living species, in which two types of cyclic catalysts play a crucial role. The one is the zwitterionic $N$-heterocyclic carbene $8,21,22$ or cyclic tin dialkoxide ${ }^{23-26}$ for initiating ring-opening polymerization of lactone or carbosiloxane to cyclic polymers with controlled number-average molecular weight $\left(M_{n}\right)$, narrow polydispersity index (PDI), and various topological structures; the other is cyclic Ru-based metathesis catalyst $\mathrm{t}^{2,3,9}$ for initiating ring-expansion metathesis polymerization (REMP) of cyclic olefins to cyclic polyolefins, where monomer insertion into a reactive or weak bond expands the cycle and avoids the formation of linear coproducts ${ }^{12,13}$, and the cyclic polymer can either retain the propagating species or remove the catalysts by a back-biting or intramolecular chain transfer reaction in these cases ${ }^{12}$. REMP opens undoubtedly an attractive way to directly achieving cyclic polymers with high $M_{\mathrm{n}}$, narrow PDI, and high purity in a normal reactant concentration $\left(>0.1 \mathrm{~mol} \mathrm{~L}^{-1}\right)$. Nonetheless, the formidable synthesis challenge of cyclic catalyst make this approach hard to be popularized. Therefore, it is envisioned for designing a facile synthetic route to cyclic polymers by the commercial Grubbs catalyst.

As a class of double-stranded polymers, ladderphane structure $^{27-30}$, constituted of multiple layers of rigid linkers connected to two polymeric backbones, has two independent propagating carbene ends in ring-opening metathesis polymerization (ROMP) process, which can further initiate the monofunctional monomers to form the $\mathrm{AB}_{2}$-type block copolymer, where ladderphane block $A$ is a double-stranded segment and block $B$ is a single-stranded segment ${ }^{31-33}$. Because polynorbornene (PNBE) chain with $\mathrm{N}$-arylpyrrolidine pendants adopted a rigid rod-like structure ${ }^{34,35}$, the two B blocks attracted by the $\pi-\pi$ stacking effect of pendants, resulting in that the two end groups of B blocks are in close proximity to each other.

Herein, we demonstrate that if the monofunctional monomer is completely reacted and the two propagating carbene ends of block $\mathrm{B}$ are maintained living feature in the process, when the difunctional monomer is added again into the living reaction system, a new ladderphane $\mathrm{A}$ was formed and served as the blocking unit to cyclize the linear $\mathrm{AB}_{2}$ copolymer intermediate. As a result, the monocyclic block copolymer $\mathrm{AB}_{2} \mathrm{~A}$ could be generated in such sequential addition of di- and monofunctional monomers, and this strategy could be defined as the blocking-cyclization technique (Fig. 1c). Interestingly, when the di- and monofunctional monomers are alternately added one by one into the living reaction system, the multicyclic block copolymers $\mathrm{A}\left(\mathrm{B}_{2} \mathrm{~A}\right)_{x}$ are readily achieved in a controlled one-pot process. This blocking-cyclization technique is different from the previous two cyclization techniques, and possesses some distinguishing features: (i) cyclization is realized by conventional ROMP, and the used Grubbs catalyst is commercially available, (ii) using ladderphane as the cyclizing unit to ensure the efficient cyclization and high purity cyclic structure, (iii) a relatively high monomer concentration is permitted (initial concentration $>$ $10^{-4} \mathrm{~mol} \mathrm{~L}^{-1}$, and the total concentration up to $0.2-1.6 \times 10^{-2} \mathrm{~mol}$ $\mathrm{L}^{-1}$ ), (iv) without the separation and purification treatments of linear polymer precursor, and (v) the ring size and ring number are regulated by a simple process. In brief, the prominent feature of this technique is that the cyclization multiply happens in situ on the two ends of polymer intermediate containing living species, and the propagating ladderphane is simultaneously served as the cyclizing unit. Therefore, the developed blocking-cyclization strategy could be considered as the third route and a versatile platform to cyclic polymers by commercial Grubbs catalyst and conventional ROMP.

\section{Results}

Blocking-cyclization technique. As a macrocyclization strategy, the effectiveness of blocking-cyclization technique for synthesizing cyclic polymer should be evaluated systematically. It is astonishing to find that this technique possessed a versatility for preparing monocyclic $c$ - $\left[\mathbf{P B N P}-(b-\mathbf{P T N P})_{2}-b\right.$-PBNP $]$ and multicyclic $c$ - $\left[\mathbf{P B N P}-\left((b-\mathbf{P T N P})_{2}-b-\mathbf{P B N P}\right)_{x}\right]$ polymers by the thirdgeneration Grubbs catalyst (Ru-III)-mediated successive ROMP of di- and monofunctional norbornene (NBE) derivatives, bis (norbornene pyrrolidine phenyl perylene bisimide) (BNP) containing the rigid perylene bisimide (PBI) linker and N-3,5-bis (trifluoromethyl)biphenyl-norbornene pyrrolidine (TNP), as depicted in Fig. 2 and Supplementary Fig. 1. The experimental details are described in Supplementary Methods. 

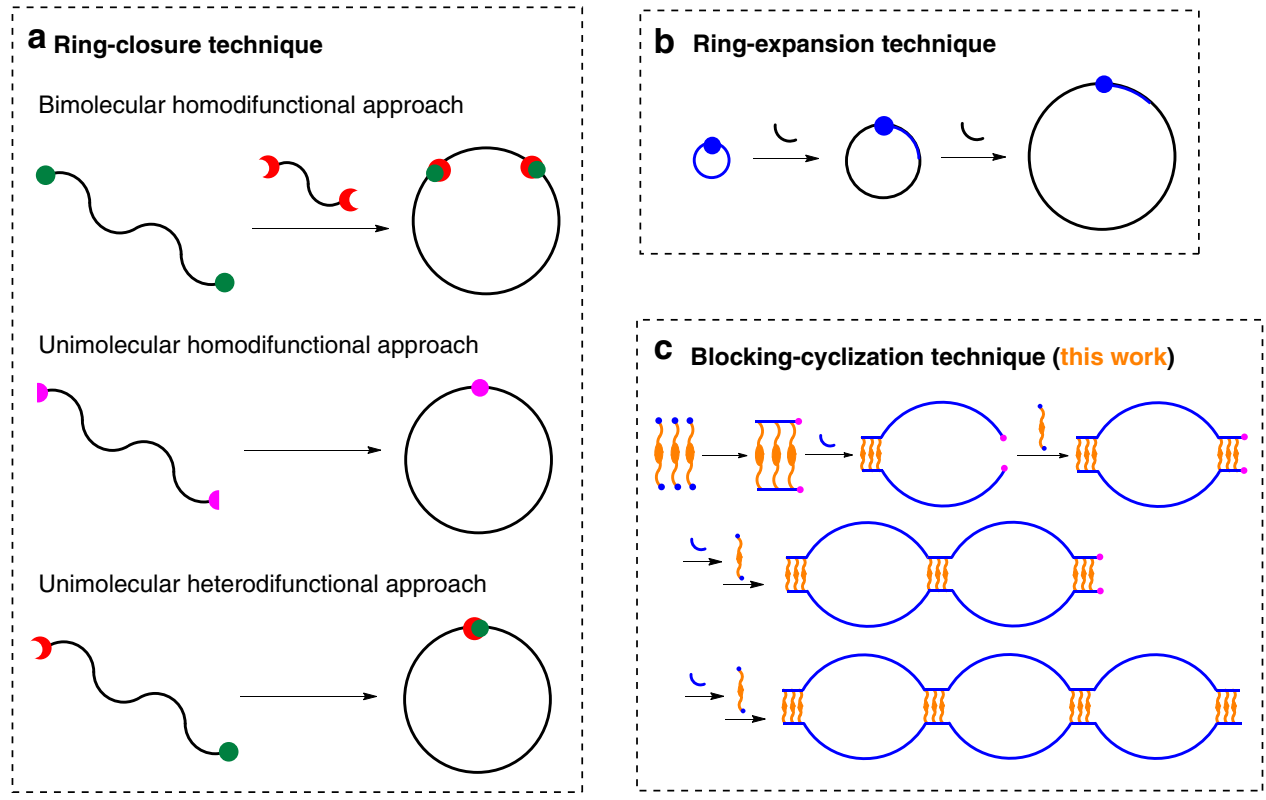

Fig. 1 Schematic representation of different techniques for the preparation of cyclic polymers. a Ring-closure. b Ring-expansion. c Blocking-cyclization
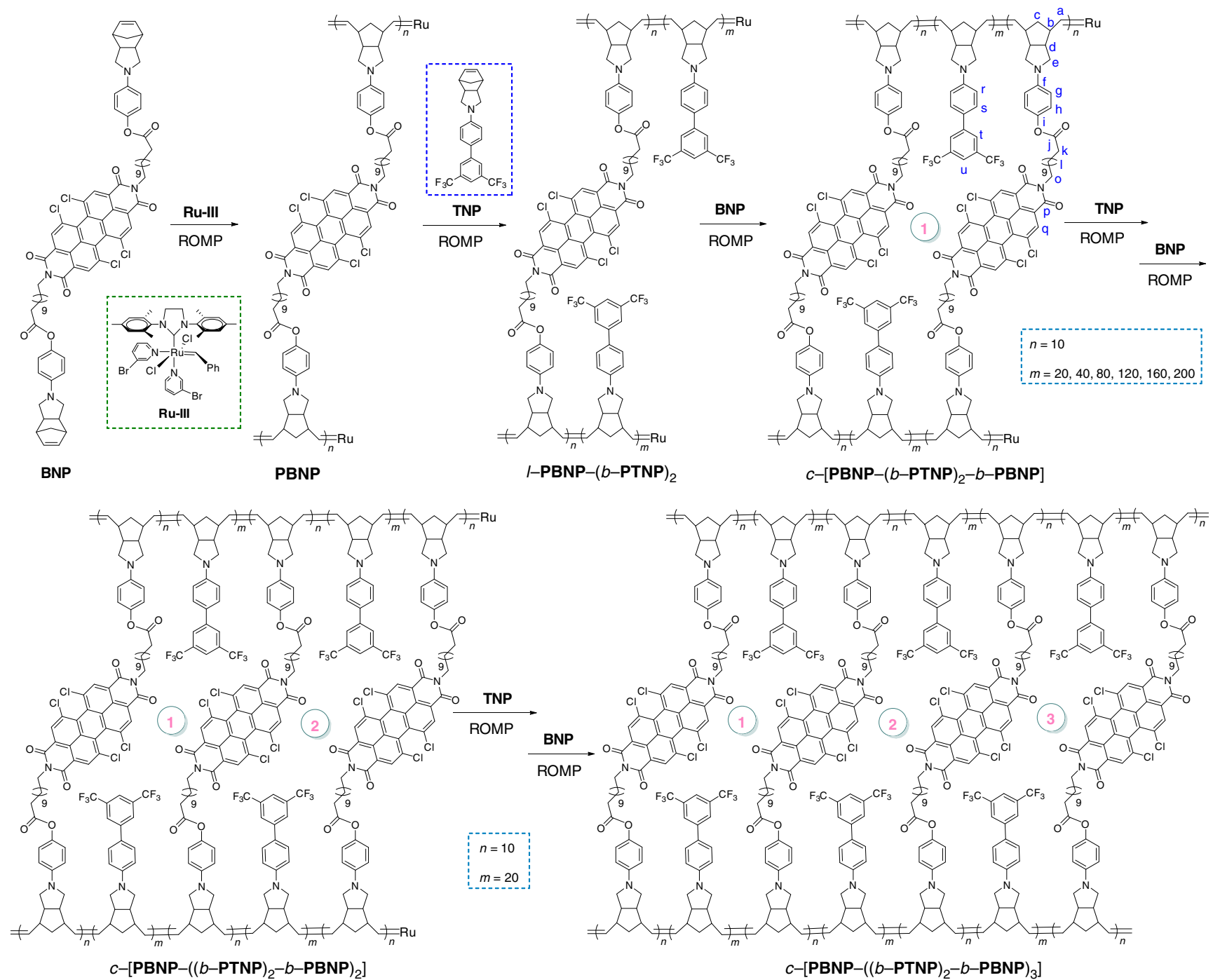

Fig. 2 Blocking-cyclization process. Syntheses of mono-, bis-, and tricyclic polymers by successive ROMP 
Synthesis and characterization of monocyclic polymers. As an initial attempt, the linear block copolymer $l$-PBNP $40^{-}(b-$ $\left.\mathbf{P T N P}_{20}\right)_{2}$ with short chain length and its cyclic counterpart $c$ $\left[\mathbf{P B N P}_{20}-\left(b-\mathbf{P T N P}_{20}\right)_{2}-b-\mathbf{P B N P} \mathbf{P}_{20}\right]$ were prepared by ROMP of difunctional BNP and monofunctional TNP with the feed ratios ([BNP]:[TNP]:[BNP]:[Cat]) of 20:20:0:1 and 10:20:10:1 (entries 1 and 2, Table 1), respectively. According to the feed ratio, the theoretical block ratio of PBNP/PTNP should be 40:40. By integrating the peak signals related to the aromatic protons $\left(\mathrm{H}_{\mathrm{q}}\right)$ on PBI linker at 8.72-8.54 ppm and those on bis(trifluoromethyl) biphenyl $\left(\mathrm{H}_{\mathrm{s}+\mathrm{t}+\mathrm{u}}\right)$ at $8.09-7.34 \mathrm{ppm}$ in ${ }^{1} \mathrm{H}$ NMR spectra (Supplementary Fig. 2a, b), as expected, the actual PBNP/PTNP ratios of linear and cyclic polymers were separately $40: 41.3$ and 40:44.8, which were similar to each other and almost consistent with the theoretical block ratios, indicating that the polymerization was well-controllable and the chain-transfer reaction in Ru-IIImediated ROMP of NBE derivatives rarely occurred at room temperature ${ }^{36}$. In other words, the repeat units of cyclic polymer and the corresponding linear counterpart should be consistent, because of the same feeding ratio of monomer to catalyst. Differently, the GPC curves (Supplementary Fig. 3) provided the $M_{\mathrm{n}} \mathrm{s}$ of 32.0 and $25.6 \mathrm{~kg} \mathrm{~mol}^{-1}$ for linear and cyclic copolymers (entries 1 and 2, Table 1), respectively, which was considered as a clear evidence for cyclic polymer with a longer elution time due to its smaller hydrodynamic volume compared with the linear analogue, while the precise $M_{\mathrm{n}, \mathrm{NMR}}$ could not be calculated from the ${ }^{1} \mathrm{H}$ NMR spectra by the end group analysis, because of the overlap for the signals of phenyl group on the chain end with those of aryl group.

When further analyzing the ${ }^{1} \mathrm{H}$ NMR spectrum of $c-\left[\mathbf{P B N P}_{20^{-}}\right.$ $\left(b \text {-PTNP }{ }_{20}\right)_{2}-b$ - $\left.\mathbf{P B N P}_{20}\right]$ under the initial concentration $\left(1 \times 10^{-3}\right.$ mol L ${ }^{-1}$ ) of difunctional BNP (Supplementary Fig. 2b), the weak signals of olefinic protons on the NBE ring at $6.2 \mathrm{ppm}$ were still observed. By integrating the ${ }^{1} \mathrm{H}$ NMR signals of olefinic protons at $6.2 \mathrm{ppm}$ and those on the main chain of $\operatorname{PNBE}\left(\mathrm{H}_{\mathrm{a}}\right)$ at $5.54-5.27 \mathrm{ppm}$, the molar ratio of the double bond residue on NBE to those of PNBE backbone was about 1:20, indicating that the cyclization of linear intermediate was mainly conducted and the second ladderphane PBNP was formed actually, even if there was a partial defective structure (Supplementary Fig. 4a). If polymerization occurred unlike this case, then polymer will have either a linear structure with a number of residual olefinic protons on the NBE ring and a larger hydrodynamic volume (Supplementary Fig. $4 \mathrm{~b}$ ) or a doubled $M_{\mathrm{n}}$ value (Supplementary Fig. 4c), which were all in contradiction with the results of ${ }^{1} \mathrm{H}$ NMR and GPC analyses, meaning that the latter two cases should be of inexistence.

The high reactant concentration and excessive difunctional monomer may be the key factors to cause the flawed structure of second ladderphane in polymerization process ${ }^{30}$. To avoid this issue, a simple way was tried by reducing the initial BNP concentration to $5 \times 10^{-4} \mathrm{~mol} \mathrm{~L}^{-1}$ (entry 3, Table 1). As expected, the integral area ratio of olefinic protons from the ${ }^{1} \mathrm{H}$ NMR spectrum (Supplementary Fig. 2c) decreased to 1:50, implying that the unreacted NBE group was further reduced, whereas these results were still not satisfactory as far as the perfect cyclic structure is concerned. Surprisingly, when the initial feed ratio of BNP to catalyst was halved to $5: 1$ (entry 5 , Table 1 ), the signal of olefinic protons on the NBE ring at $6.2 \mathrm{ppm}$ disappeared completely (Fig. 3b), indicating that the well-defined second ladderphane structure was indeed formed and the proposed defective cyclic structure (Supplementary Fig. 4a) was completely avoided under this optimum polymerization conditions. The calculated PBNP/PTNP ratios of 20:39.2 and 20:37.2 (entries 4 and 5 , Table 1) by the ${ }^{1} \mathrm{H}$ NMR analysis were compliant with the feed ratio of 20:40. Importantly, only a signal peak at 5.54-5.27 ppm in ${ }^{1} \mathrm{H}$ NMR spectra (Fig. 3a, b) and a solely absorption band at $965 \mathrm{~cm}^{-1}$ (but no absorption appearance at
$720 \mathrm{~cm}^{-1}$ for the cis double bond) in IR spectra (Supplementary Fig. 5) for the trans double bonds on PNBE backbone of block copolymers were observed, demonstrating that the PNBE backbone was highly trans-configuration. Raman spectra of polymers (Supplementary Fig. 6) showed the characteristic peak at $1606 \mathrm{~cm}$ ${ }_{-1}^{-1}$ assigned to the trans $\mathrm{C}=\mathrm{C}$ vibration (while nearly no $\operatorname{cis} \mathrm{C}=\mathrm{C}$ vibration appeared at about $1580 \mathrm{~cm}^{-1}$ ) in the PNBE backbone ${ }^{37}$, which is consistent with the results of ${ }^{1} \mathrm{H}$ NMR and IR analyses. Besides, the ${ }^{13} \mathrm{C}$ NMR spectra (Fig. 3c, d) of block copolymers showed that the signals of methylene carbon $\left(\mathrm{C}_{\mathrm{c}}\right)$ were observed as only one single peak at $34.5-34.0 \mathrm{ppm}$, suggesting that the backbone had high stereoregularity mostly because the size of endo-N-arylpyrrolidine NBE moiety in BNP and TNP matched well with the space requirement to control the stereoselectivity of single- and double-stranded PNBE chains during ROMP process ${ }^{30-33,38,39}$.

By comparing the GPC traces (Fig. 4a), the $M_{\mathrm{n}}$ of cyclic polymer was lower than that of linear analogue $(15.0 \mathrm{vs} 22.1 \mathrm{~kg}$ $\mathrm{mol}^{-1}$ ) due to its smaller hydrodynamic volume. The results of ${ }^{1} \mathrm{H}$ NMR and GPC analyses proved that the effective cyclization was performed successfully. Inspired by the successful preparation of cyclic polymer with short repeat units, the loading of monofunctional TNP increased to enlarge the cyclic units and evaluate the universality of the proposed method. When the [TNP]/[Cat] ratios raised to 40, 80, 120, and 160 (entries 6-13, Table 1$)$, the $M_{\mathrm{n}} \mathrm{s}$ of resulting four cyclic polymers $c$ - $\left[\mathbf{P B N P}_{10^{-}}(b-\right.$ $\left.\left.\mathbf{P T N P}_{x}\right)_{2}-b-\mathbf{P B N P}_{10}\right](x=40,80,120$, and 160$)$ were $43.7,67.2$, 84.5 , and $96.8 \mathrm{~kg} \mathrm{~mol}^{-1}$ (Supplementary Fig. 7), respectively, which were lower than those $(48.6,81.8,99.2$, and $115.2 \mathrm{~kg}$ mol $\left.{ }^{-1}\right)$ of their linear counterparts $l$ - $\mathbf{P B N P}_{20}\left(b-\mathbf{P T N P}_{x}\right)_{2}$. The absolute molecular weight $\left(M_{\mathrm{a}}\right)$ and intrinsic viscosity of representative $\quad l$ - $\mathbf{P B N P}_{20^{-}}\left(b-\mathbf{P T N P}_{160}\right)_{2}$ and $c-\left[\mathbf{P B N P}_{10^{-}}(b-\right.$ $\left.\mathbf{P T N P}_{160}\right)_{2}-b$-PBNP 10 ] were also obtained by GPC analysis with dual angle laser light scattering and viscosity detectors (Fig. $4 \mathrm{~b}$ ). The linear and cyclic polymers had a similar $M_{\mathrm{a}}$ (158.6 vs $154.9 \mathrm{~kg} \mathrm{~mol}^{-1}$ ) because of the same feed ratio of monomer to catalyst, and the $M_{\mathrm{a}}$ values were about 1.5 times larger than those of the related $M_{\mathrm{n}}$. The more physically compacted cyclic polymer possessed smaller hydrodynamic volume and lower intrinsic viscosity than their linear analogues (Fig. 4c, d), and the viscosity discrepancy between the linear and cyclic polymers was extended as the weight-average molecular weight $\left(M_{\mathrm{w}}\right)$ increase (Fig. $4 \mathrm{~d}$ ). In addition, the ${ }^{1} \mathrm{H}$ NMR spectra of $c-\left[\mathbf{P B N P}_{10^{-}}\left(b-\mathbf{P T N P}_{x}\right)_{2}-b\right.$ $\mathbf{P B N P}_{10}$ ] showed that the well-defined second ladderphane in all cyclic polymers was formed, because the signal of residual olefinic protons on the NBE ring was not observed (Supplementary Fig. 8). The actual PBNP/PTNP ratios of cyclic polymers evaluated by their ${ }^{1} \mathrm{H}$ NMR spectra were $20: 68.2,20: 148.0$, 20:234.4, and 20:328.6 successively, which increased with the TNP loading increase and were much closer to the corresponding theoretical block ratios. Furthermore, the representative ${ }^{1} \mathrm{H}$ NMR spectrum of $c$ - $\left[\mathbf{P B N P}_{10^{-}}\left(b-\mathbf{P T N P}_{160}\right)_{2}-b\right.$ - $\left.\mathbf{P B N P}{ }_{10}\right]$ showed no signal of olefinic protons on the NBE ring at $6.2 \mathrm{ppm}$ even if the coherent accumulation number was added up to 5000 (Supplementary Fig. 9), suggesting that the second ladderphane structure was well-defined, and the proposed defective cyclic structure or impossible structures (Supplementary Fig. 4) were effectively ruled out, otherwise, the signal of unreacted olefinic protons on the NBE ring should be detected (like as those in Supplementary Figs. $2 \mathrm{~b}$ and $2 \mathrm{c}$ with $5 \%$ and $2 \%$ of residual NBE groups, respectively). When the $[\mathrm{TNP}] /[\mathrm{Cat}]$ ratio further increased to 200 (entries 14 and 15 , Table 1$), c$ - $\left[\mathbf{P B N P}_{10^{-}}\left(b-\mathbf{P T N P}_{200}\right)_{2}-b\right.$ PBNP $_{10}$ ] has an increased $M_{\mathrm{n}}$ of $110.8 \mathrm{~kg} \mathrm{~mol}^{-1}$, which was also lower than that $\left(122.3 \mathrm{~kg} \mathrm{~mol}^{-1}\right)$ of its linear analogous $l$ $\mathbf{P B N P}_{20^{-}}\left(b-\mathbf{P T N P}_{200}\right)_{2}$ with the yield of about $85 \%$, and the resulting PBNP/PTNP ratio of 20:374.7 was lower than the 
Table 1 Characteristics for linear and cyclic polymers

\begin{tabular}{|c|c|c|c|c|c|c|}
\hline Entry & Polymer & $\begin{array}{l}\text { [BNP]:[TNP]:[BNP]:[TNP]: } \\
{[B N P]:[T N P]:[B N P]:[C a t]^{a}}\end{array}$ & [PBNP]:[PTNP] & $M_{\mathrm{n}}^{\mathrm{c}}\left(\mathrm{kg} \mathrm{mol}^{-1}\right)$ & PDIC & Yield (\%) \\
\hline $1^{d}$ & I-PBNP $_{40}-\left(b-\mathbf{P T N} \mathbf{P}_{20}\right)_{2}$ & $20: 20: 0: 0: 0: 0: 0: 1$ & $40: 41.3$ & 32.0 & 1.35 & 95 \\
\hline $2^{e}$ & $c-\left[\mathbf{P B N P}_{20}-\left(b-\mathbf{P T N P _ { 2 0 }}\right)_{2}-b-\mathbf{P B N P}_{20}\right]$ & $10: 20: 10: 0: 0: 0: 0: 1$ & $40: 44.8$ & 25.6 & 1.31 & 93 \\
\hline $3^{f}$ & $c-\left[\mathbf{P B N P}_{20}-\left(b-\mathbf{P T N P}_{20}\right)_{2}-b-\mathbf{P B N P}_{20}\right]$ & $10: 20: 10: 0: 0: 0: 0: 1$ & $40: 48.9$ & 22.9 & 1.36 & 88 \\
\hline $4^{d}$ & I-PBNP $_{20}-\left(b-\mathbf{P T N P}_{20}\right)_{2}$ & 10:20:0:0:0:0:0:1 & $20: 39.2$ & 22.1 & 1.32 & 93 \\
\hline $5^{f}$ & $c-\left[\mathbf{P B N P}_{10}-\left(b-\mathbf{P} \mathbf{T} \mathbf{N P}_{20}\right)_{2}-\mathrm{b}-\mathbf{P B N} \mathbf{P}_{10}\right]$ & 5:20:5:0:0:0:0:1 & $20: 37.2$ & 15.0 & 1.28 & 91 \\
\hline $6^{d}$ & I-PBNP $\mathbf{P}_{20}-\left(b-\mathbf{P T N P}_{40}\right)_{2}$ & 10:40:0:0:0:0:0:1 & - & 48.6 & 1.25 & 93 \\
\hline $7^{f}$ & $c-\left[\mathbf{P B N P}_{10}-\left(b-\mathbf{P} \mathbf{T} \mathbf{N P}_{40}\right)_{2}-b-\mathbf{P B N P}_{10}\right]$ & 5:40:5:0:0:0:0:1 & $20: 68.2$ & 43.7 & 1.31 & 92 \\
\hline $8^{d}$ & I-PBNP ${ }_{20}-\left(b-\mathbf{P T N P}_{80}\right)_{2}$ & 10:80:0:0:0:0:0:1 & - & 81.8 & 1.45 & 92 \\
\hline $9^{f}$ & $c-\left[\mathbf{P B N P}_{10}-\left(b-\mathbf{P T N}_{80}\right)_{2}-b-\mathbf{P B N P}_{10}\right]$ & $5: 80: 5: 0: 0: 0: 0: 1$ & $20: 148.0$ & 67.2 & 1.43 & 95 \\
\hline $10^{d}$ & I-PBNP $\mathbf{P}_{20}-\left(b-\mathbf{P T N} \mathbf{P}_{120}\right)_{2}$ & 10:120:0:0:0:0:0:1 & - & 99.2 & 1.39 & 91 \\
\hline $11^{f}$ & $c-\left[\mathbf{P B N P}_{10}-\left(\mathrm{b}-\mathbf{P} \mathbf{T} \mathbf{N P}_{120}\right)_{2}-\mathrm{b}-\mathbf{P B N P} \mathbf{P}_{10}\right]$ & 5:120:5:0:0:0:0:1 & $20: 234.4$ & 84.5 & 1.41 & 91 \\
\hline $12^{d}$ & I-PBNP $_{20}-\left(b-\mathbf{P T N} \mathbf{P}_{160}\right)_{2}$ & 10:160:0:0:0:0:0:1 & - & 115.2 & 1.43 & 95 \\
\hline $13^{f}$ & $c-\left[\mathbf{P B N P}_{10}-\left(b-\mathbf{P T} \mathbf{N P}_{160}\right)_{2}-b-\mathbf{P B N P}_{10}\right]$ & $5: 160: 5: 0: 0: 0: 0: 1$ & $20: 328.6$ & 96.8 & 1.38 & 94 \\
\hline $14^{d}$ & I-PBNP $20-\left(b-\mathbf{P} \mathbf{T} \mathbf{N P}_{200}\right)_{2}$ & 10:200:0:0:0:0:0:1 & - & 122.3 & 1.45 & 83 \\
\hline $15^{f}$ & $c-\left[\mathbf{P B N P}_{10}-\left(\mathrm{b}-\mathbf{P} \mathbf{T} \mathbf{N P}_{200}\right)_{2}-\mathrm{b}-\mathbf{P B N P}_{10}\right]$ & $5: 200: 5: 0: 0: 0: 0: 1$ & $20: 374.7$ & 110.5 & 1.36 & 85 \\
\hline $16^{d}$ & I-PBNP $_{20}-\left(b-\mathbf{P T N} \mathbf{P}_{160}\right)_{2}$ & $10: 160: 0: 0: 0: 0: 0: 1$ & - & 110.2 & 1.38 & 91 \\
\hline $17^{f}$ & $c-\left[\mathbf{P B N P}_{10}-\left(b-\mathbf{P T N} \mathbf{P}_{160}\right)_{2}-b-\mathbf{P B N P}_{10}\right]$ & $5: 160: 5: 0: 0: 0: 0: 1$ & - & 93.1 & 1.31 & 89 \\
\hline $18^{d}$ & I-PBNP $\mathbf{P}_{30}-\left(b-\mathbf{P T N P}_{40}\right)_{2}$ & 15:40:0:0:0:0:0:1 & $30: 81.7$ & 58.9 & 1.39 & 94 \\
\hline $19^{f}$ & $c-\left[\mathbf{P B N P}_{10}-\left(\left(\mathrm{b}-\mathbf{P} \mathbf{T} \mathbf{N P}_{20}\right)_{2}-\mathrm{b}-\mathbf{P B} \mathbf{N} \mathbf{P}_{10}\right)_{2}\right]$ & 5:20:5:20:5:0:0:1 & $30: 81.1$ & 38.2 & 1.35 & 94 \\
\hline $20^{d}$ & I-PBNP $_{40}-\left(b-\mathbf{P T N P}_{60}\right)_{2}$ & $20: 60: 0: 0: 0: 0: 0: 1$ & $40: 89.5$ & 87.4 & 1.48 & 83 \\
\hline $21^{f}$ & $c-\left[\mathbf{P B N P}_{10}-\left(\left(b-\mathbf{P T} \mathbf{N P}_{20}\right)_{2}-\mathrm{b}-\mathbf{P B N P}_{10}\right)_{3}\right]$ & $5: 20: 5: 20: 5: 20: 5: 1$ & $40: 86.8$ & 44.0 & 1.36 & 85 \\
\hline $\begin{array}{l}\text { Polymeri } \\
30 \text { min) } \\
\text { PBNP } 10 \text { ) } \\
\text { aThe fee } \\
\text { bThe blo } \\
\text { cDetermi } \\
\text { d[BNP }]_{0} \\
\text { e[BNP] }\end{array}$ & $\begin{array}{l}\text { ratios of monomers to catalyst for polymerization } \\
\text { atio of PBNP to PTNP by }{ }^{1} \mathrm{H} \text { NMR spectroscopy an } \\
\text { by GPC in THF relative to monodispersed polystyr } \\
2 \times 10^{-3} \text { mol L-1 refers to the initial monomer conce } \\
\times 10^{-3} \mathrm{~mol} \mathrm{~L}^{-1} \text { refers to the initial monomer concer } \\
\times 10^{-4} \mathrm{~mol} \mathrm{~L}^{-1} \text { refers to the initial monomer concer }\end{array}$ & $\begin{array}{l}\text { - and monofunctional monomers in s } \\
\text { s } \\
\text { standards } \\
\text { ion of BNP } \\
\text { on of BNP } \\
\text { on of BNP }\end{array}$ & lition manner & - & $\mathbf{P}_{10}-(()$ & $\begin{array}{l}{ }_{20}(30+30+ \\
\left.\mathbf{N P}_{20}\right)_{2}-b-\end{array}$ \\
\hline
\end{tabular}

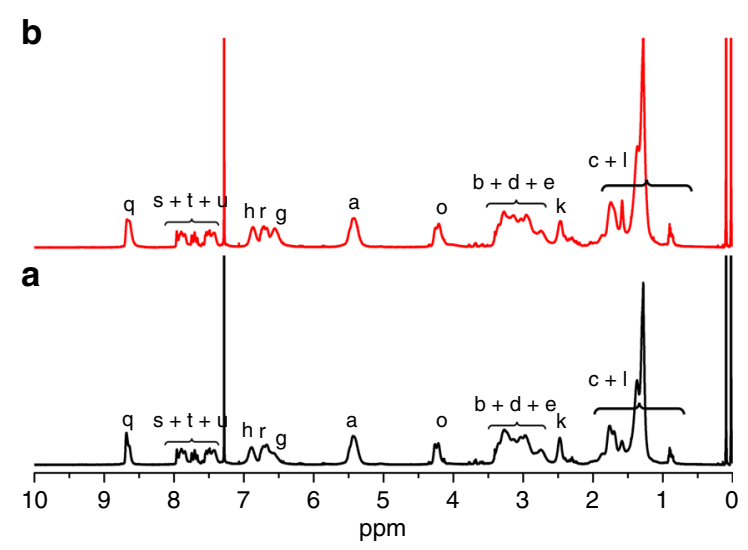

Fig. 3 The NMR spectra of linear and monocyclic polymers. ${ }^{1} \mathrm{H}(\mathbf{a}, \mathbf{b})$ and ${ }^{13} \mathrm{C}(\mathbf{c}, \mathbf{d})$ NMR spectra of $l$-PBNP $20-\left(b-\mathbf{P T N P}_{20}\right)_{2}(\mathbf{a}, \mathbf{c})$ and $c-\left[\mathbf{P B N P}_{10}-(b-\right.$ $\left.\left.\mathbf{P T N P}_{20}\right)_{2}-b-\mathbf{P B N P}_{10}\right](\mathbf{b}, \mathbf{d})$ in $\mathrm{CDCl}_{3}$

theoretical value of 20:400. The PDIs of all polymers were narrow between 1.25 and 1.45, and the trans-configuration did not change in the successive ROMP process for the preparation of linear and cyclic polymers.

These results strongly proved that the cyclic polymers with small to large ring size and perfect ring structure could be achieved successfully by the blocking-cyclization technique.

In general, the chain-transfer rate was much slower than the chain-propagation rate in ROMP of NBE derivatives initiated by Ru-III at room temperature ${ }^{36,40}$, namely, it was rare to encounter the problem that the active species at the end of polymer chains were transferred or the chain termination reactions happened before cyclizing the linear intermediate. To preliminarily examine the influence of temperature on chain-transfer reaction, ROMP of BNP and TNP with the feed ratio of 10:160 at $-20^{\circ} \mathrm{C}$ (entries 16 d

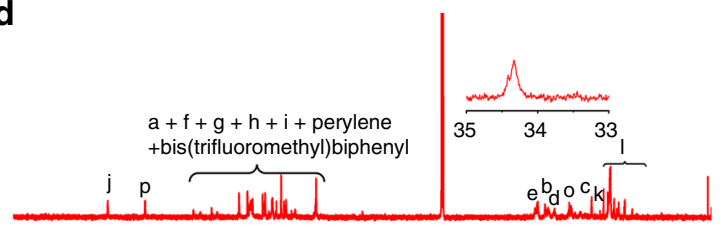

C

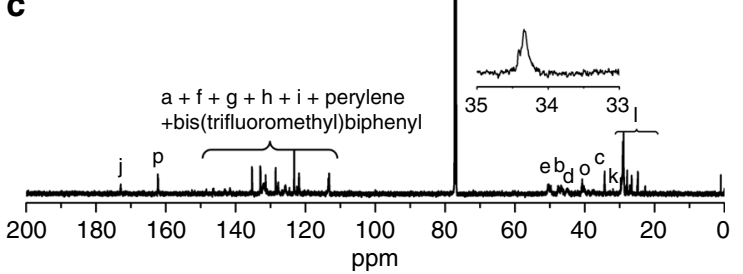

and 17, Table 1) was selected as a representative case, generating linear $l$-PBNP $\mathbf{P O}^{-}\left(b-\mathbf{P T N P} \mathbf{T N 0}_{160}\right)_{2}$ and its cyclic counterpart $c$ $\left[\mathbf{P B N P}_{10^{-}}\left(b-\mathbf{P T N P}_{160}\right)_{2}-b-\mathbf{P B N P}_{10}\right]$ with the $M_{\mathrm{n}} \mathrm{s}$ and PDIs of $110.2 \mathrm{~kg} \mathrm{~mol}^{-1}$ and 1.38 as well as $83.1 \mathrm{~kg} \mathrm{~mol}^{-1}$ and 1.31 (Supplementary Fig. 10), respectively, which were slightly lower and narrower than those of the corresponding polymers obtained with the same feed ratio at $30^{\circ} \mathrm{C}$ (entries 12 and 13 , Table 1), predicating that the chain transfer reaction was unconspicuous at room temperature, and the negative effect of temperature on the formation of cyclic polymers could be ignored. In a word, the synthesis of monocyclic polymers with short to long repeat units was realized by ROMP under the conventional reaction conditions.

Synthesis and characterization of bis- and tricyclic polymers. Compared to the traditional techniques for synthesizing cyclic 

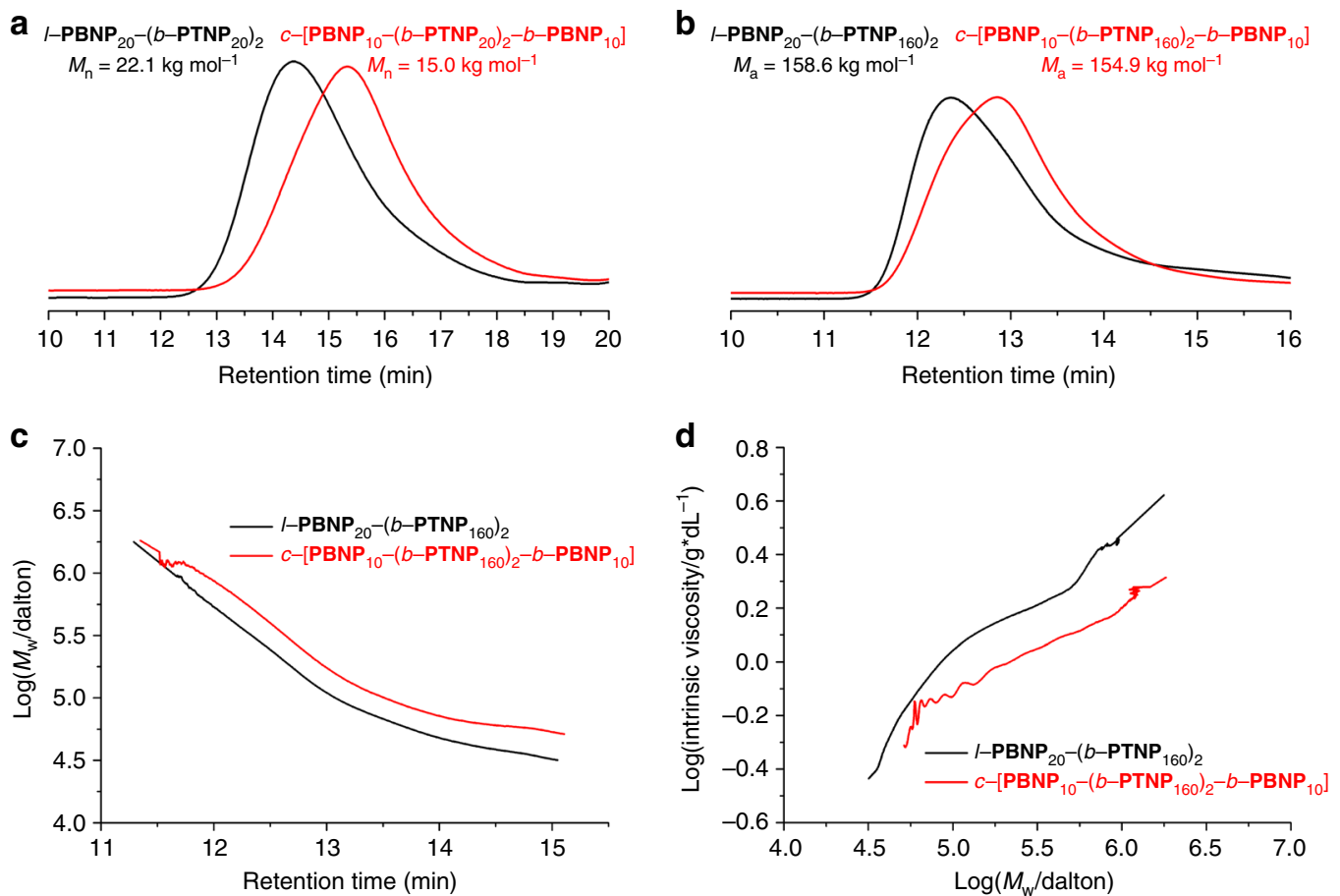

Fig. 4 GPC traces of linear and monocyclic polymers. a Number-average molecular weight $\left(M_{n}\right)$. b Absolute molecular weight $\left(M_{a}\right)$ vs elution time (eluent $=$ THF; the reported molecular weights were determined by light-scattering methods and are therefore considered absolute). c Plots of log weight-average molecular weight $\left(M_{\mathrm{w}}\right)$ vs elution time. d Plots of log intrinsic viscosity vs log $M_{\mathrm{w}}$ (Mark-Houwink plot)

polymers, the predominant advantage of the blocking-cyclization technique is the easy synthesis of multicyclic polymers with controlled $M_{\mathrm{n}}$ by successive ROMP of di- and monofunctional monomers in one-pot procedure. On the basis of the optimized conditions for monocyclic polymers under low monomer loading, the blocking-cyclization technique was tried to prepare bis- and tricyclic polymers, $c$ - $\left[\mathbf{P B N P}_{10^{-}}\left(\left(b-\mathbf{P T N P}_{20}\right)_{2}-b-\mathbf{P B N P} \mathbf{P}_{10}\right)_{2}\right]$ and $c$ $\left[\mathbf{P B N P}_{10^{-}}\left(\left(b-\mathbf{P T N P}_{20}\right)_{2}-b-\mathbf{P B N P}_{10}\right)_{3}\right]$, by successive ROMP via alternating monomer addition in five and seven times, respectively. Similarly, comparing the bis- and tricyclic polymers with their linear counterparts $l$ - $\mathbf{P B N P} \mathbf{P}_{30^{-}}\left(b-\mathbf{P T N P}_{40}\right)_{2}$ and $l$ - $\mathbf{P B N P} \mathbf{P N}_{40^{-}}$ $\left(b \text {-PTNP }{ }_{60}\right)_{2}$, the approximated PBNP/PTNP ratios for the above two pairs of polymers were calculated to be $30: 81.1$ vs $30: 81.7$ and 40:86.8 vs $40: 89.5$ (entries $18-21$, Table 1 ) by the ${ }^{1} \mathrm{H}$ NMR analysis (Supplementary Figs. 26 and 27), and the $M_{\mathrm{n}} \mathrm{s}$ (Supplementary Figs. 28 and 29) of cyclic polymers were less than those of linear analogues $\left(38.2 \mathrm{vs} 58.9 \mathrm{~kg} \mathrm{~mol}^{-1}\right.$ and $44.0 \mathrm{vs} 87.4 \mathrm{~kg}$ $\mathrm{mol}^{-1}$, respectively), indicating that the successive cyclization was conducted effectively. What is more important, for the bis- and tricyclic polymers, the well-defined ladderphane segments were generated and thus the perfect macrocyclic structures were obtained, because the signal of residual olefinic protons on the NBE ring was never observed in ${ }^{1} \mathrm{H}$ NMR spectra (Supplementary Figs. 26 and 27). In addition, the ${ }^{1} \mathrm{H}$ NMR spectra of all polymers had only a signal peak at $5.54-5.27 \mathrm{ppm}$, and the IR spectra (Supplementary Figs. 30 and 31) showed the solely absorption band at $965 \mathrm{~cm}^{-1}$ for the trans double bond without the absorption appearance at $720 \mathrm{~cm}^{-1}$ for the cis double bond, demonstrating that the PNBE backbones were highly trans-configuration, which were similar with those of monocyclic polymers. Therefore, it can be concluded from the above investigations that the developed blocking-cyclization technique is an efficient strategy for synthesizing mono- and even multicyclic polymers.

Post-polymerization of monocyclic polymers. Post-polymerization is an effective way to modify polymers with varied structures and improved properties. As for $c$ - $\left[\mathbf{P B N P}_{10}-\left(b-\mathbf{P T N P}_{\mathrm{x}}\right)_{2}-b-\mathbf{P B N P} \mathbf{P}_{10}\right]$, it has the unsaturated PNBE backbone and could be easily modified by triazolinedione (TAD)-based Alder-ene chemistry ${ }^{41}$. Taking $c$ - $\left[\mathbf{P B N P}_{10^{-}}\left(\left(b-\mathbf{P} \mathbf{T N P}_{160}\right)_{2}-b \text {-PBNP }\right)_{10}\right]$ as an example, its post-polymerization modification was conducted to make it be transformed into the bulky POSS moiety-contained $c$ - $\left[\mathbf{P B N P}_{10^{-}}\right.$ $\left.\left(\left(b \text {-PTNP }{ }_{160}\right)_{2}-b \text {-PBNP }\right)_{10}\right]$-POSS (Supplementary Fig. 37$)$ by using the molar ratio of polyhedral oligomeric silsesquioxane propylisobutyl-1,2,4-triazoline-3,5-dione (POSS-TAD) (Supplementary Fig. 39$)$ to the double bonds on PNBE backbone (1:1). After connecting POSS moieties, the position of double bonds on the PNBE backbone of $c$ - $\left[\mathbf{P B N P}_{10}-\left(\left(b-\mathbf{P T N P}_{160}\right)_{2}-b-\mathbf{P B N P}\right)_{10}\right]-$ POSS was isomerized, and a new signal peak at $3.62-3.47 \mathrm{ppm}$ ascribed to the introduced methylene group $\left(\mathrm{H}_{\mathrm{w}}\right)$ of POSS moiety was observed in its ${ }^{1} \mathrm{H}$ NMR spectrum (Supplementary Fig. 40a) by comparison to the signals of $c-\left[\mathbf{P B N P}_{10}-\left(\left(b-\mathbf{P T N P}_{160}\right)_{2}-b-\right.\right.$ PBNP $)_{10}$ ] (Fig. 3b), clearly indicating the successful modification. In addition, by virtue of the peak area ratio of $\mathrm{H}_{\mathrm{w}}$ to that of double-bond protons $\left(\mathrm{H}_{\mathrm{a}}\right)$ on the PNBE backbone at 5.59-5.24 ppm, the quantitative incorporated POSS-TAD was calculated as around $25 \%$ in this case, which was lower than the feed ratio, because the POSS moieties attached to the PNBE backbone prevented the adjacent double bond from reacting with incoming POSS-TAD, due to the steric hindrance of bulky POSS moiety. The signals of methylene carbon $\left(\mathrm{C}_{\mathrm{c}}\right)$ in the ${ }^{13} \mathrm{C}$ NMR spectrum (Supplementary Fig. 40b) of $c$ - $\left[\mathbf{P B N P}_{10^{-}}\left(b-\mathbf{P T N P}_{20}\right)_{2}-b-\right.$ PBNP $\left._{10}\right]$-POSS were observed as three asymmetrical single peaks at $34.5-34.0 \mathrm{ppm}$, indicating the disruption of stereoregularity microstructure feature of PNBE backbone. The GPC curve showed a monomodal peak with the $M_{\mathrm{n}}$ and PDI of $206.4 \mathrm{~kg} \mathrm{~mol}$ -1 and 1.45 (Supplementary Fig. 41), respectively, and the peak position shifted to a high molecular weight region comparing to that of $c-\left[\mathbf{P B N P}_{10}-\left(\left(b-\mathbf{P} \mathbf{T N P}_{160}\right)_{2}-b-\mathbf{P B N P}\right)_{10}\right]$.

Topology of cyclic polymers. When the single block copolymer chains were dispersed uniformly in the highly diluted good solvent, the inter-chain interactions could be ignored. In dynamic light scattering (DLS) testing, the linear $l-\mathbf{P B N P}_{20}-\left(b-\mathbf{P T N P}_{20}\right)_{2}$ 
has one distinct peak with a dominating volume-average hydrodynamic diameter $\left(D_{\mathrm{h}}\right)$ of $4-5 \mathrm{~nm}$ corresponding to a single macromolecule at a low concentration of $0.1 \mathrm{mg} \mathrm{mL}^{-1}$ in $\mathrm{CHCl}_{3}$, while the $D_{\mathrm{h}}$ of cyclic $c$ - $\left[\mathbf{P B N P} \mathbf{P}_{10}-\left(\left(b-\mathbf{P T N P}_{20}\right)_{2}-b-\mathbf{P B N P} \mathbf{P B}_{10}\right)\right]$ with the same repeat units reduced to 3-4 nm (Supplementary Fig. 47). This was because that the confined PTNP segments in a single cyclic polymer molecule was easy to entangle itself by the $\pi-\pi$ stacking effect of pendants due to the closer molecular distance in comparison to the corresponding linear polymer molecule, resulting in a smaller hydrodynamic size. As the repeat units increase, the $D_{\mathrm{h}} \mathrm{s}$ of all copolymers had a slight increase and the size of cyclic polymers was still smaller than the corresponding linear polymers. When the copolymers incorporated the POSS moiety, the sizes of all copolymers increased, and DLS diagrams of copolymers displayed two peaks with a dominating $D_{\mathrm{h}}$ of about $7 \mathrm{~nm}$ and a little small $D_{\mathrm{h}}$ of about $20 \mathrm{~nm}$ in $\mathrm{CHCl}_{3}$ (Supplementary Fig. 48). Noteworthy, the $D_{\mathrm{h}} \mathrm{s}$ of POSS-modified cyclic polymers had no obvious difference with those of linear counterparts (Supplementary Table 2), because the intra-chain entanglement junctions disappeared and the POSS-modified cyclic macromolecule was free from constriction.

Further insight into the visualization of the single cyclic polymer molecule was carried out by atomic force microscopy (AFM). AFM phase and height images were a strong supporting evidence for the cyclic polymer topology ${ }^{42-44}$. Samples of $c$ $\left[\mathbf{P B N P}_{10^{-}}\left(b-\mathbf{P T N P}_{160}\right)_{2}-b-\mathbf{P B N P} \mathbf{P}_{10}\right], c-\left[\mathbf{P B N P}_{10^{-}}\left(b-\mathbf{P T N P}_{160}\right)_{2}-b-\right.$
PBNP $\left._{10}\right]$-POSS, and $l$-PBNP 20 - $\left(b \text {-PTNP }{ }_{160}\right)_{2}$-POSS were prepared by spin-coating a polymer solution at $50 \mathrm{ng} \mathrm{mL}^{-1}$ in $\mathrm{CHCl}_{3}$ onto the freshly cleaved mica. According to the feed ratio ([TNP]/ [Cat]) of 160:1, the repeat units were about 320 because the single cyclic polymer molecule had two PTNP segments. Based on the length of each repeat unit of $0.65 \mathrm{~nm}^{27}$, the circumference and diameter of macrorings were about 208 and $66 \mathrm{~nm}$, respectively. The AFM height image of unmodified $c-\left[\mathbf{P B N P}_{10}-\left(b-\mathbf{P T N P}_{160}\right)_{2^{-}}\right.$ $b$-PBNP $\left.{ }_{10}\right]$ was shown in Supplementary Fig. 49. Typically, the irregular nanoparticles with the average diameters and heights of $15-25 \mathrm{~nm}$ and $0.6-0.8 \mathrm{~nm}$ were observed, respectively, and there were no any cyclic features due to the intra-chain entanglement. When the cyclic polymers incorporated the POSS moieties on the PNBE backbone, the intra-chain entanglement of PTNP segments in $c$ - $\left[\mathbf{P B N P}_{10}-\left(b-\mathbf{P T N P}_{160}\right)_{2}-b\right.$-PBNP $\left.\mathbf{P N}_{10}\right]$-POSS was restrained, and the outer and inner diameters of macrorings could be observed as $25-35$ and $8-12 \mathrm{~nm}$ (Fig. 5a-e), respectively, which was less than the theoretical values, indicating that the cyclic polymer backbone was not fully extended. The heights of macrorings ranged between 0.6 and $0.8 \mathrm{~nm}$, and the corresponding analysis of the line scan revealed highly uniform profile features (Fig. 5f). Importantly, no any linear topology was found in Fig. 5a-e and Supplementary Fig. 50, suggesting that the adopted blocking-cyclization technique was really an effective strategy for preparing high-molecular-weight cyclic polymers.

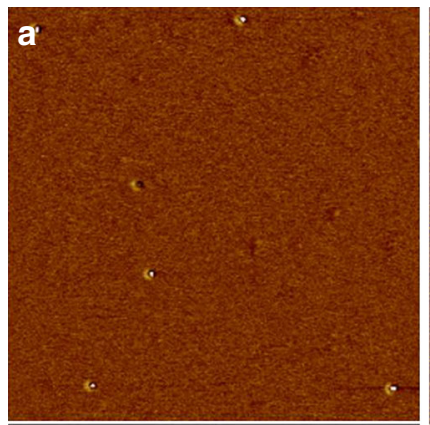

0.0

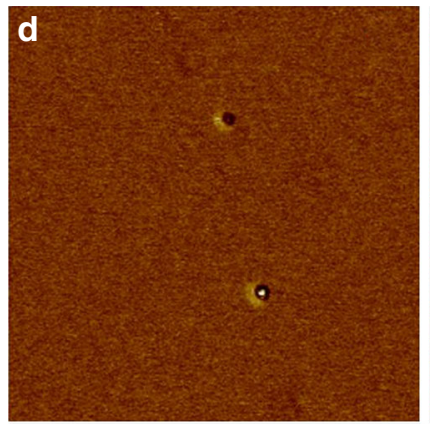

0.0

Phase

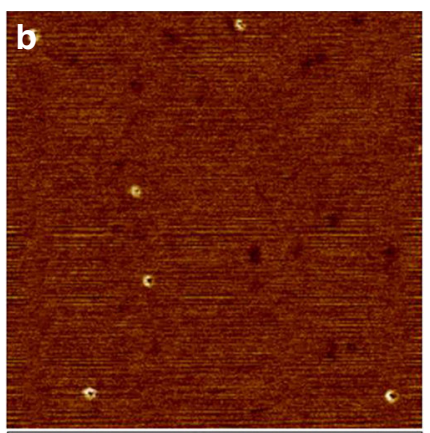

Height sensor

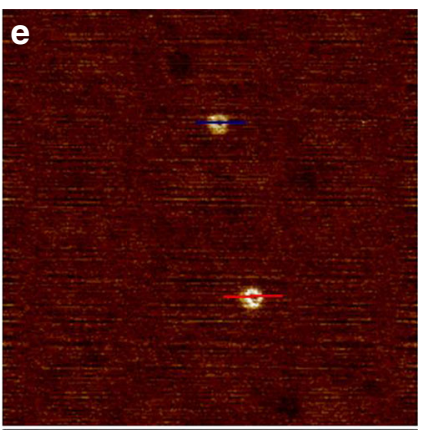

Height sensor
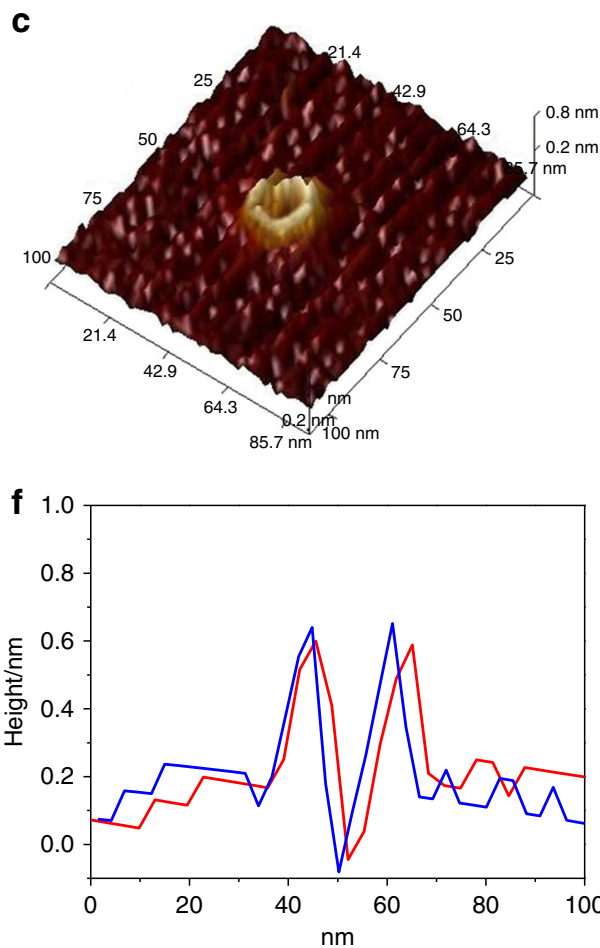

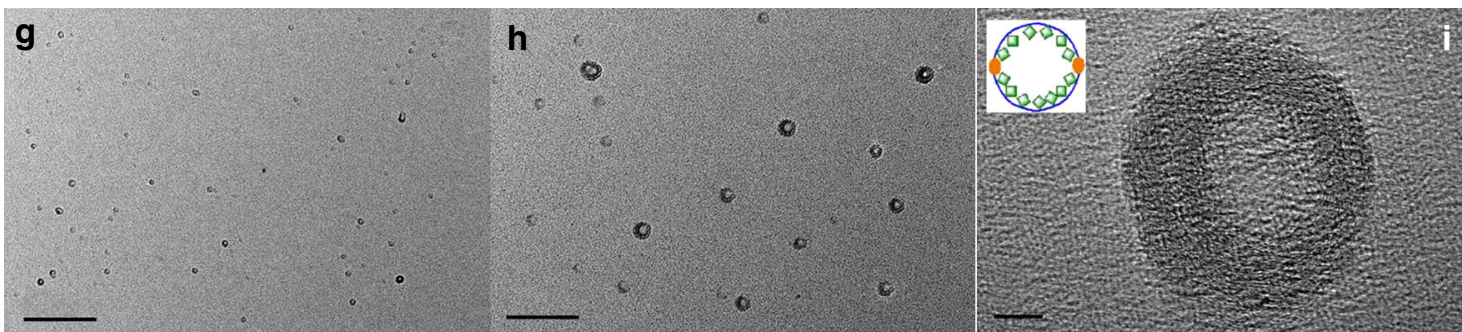

Fig. 5 Topology of monocyclic polymer. a-e AFM phase $(\mathbf{a}, \mathbf{d})$ and height $(\mathbf{b}, \mathbf{e})$ images of $c-\left[\mathbf{P B N P}_{10}-\left(b-\mathbf{P T N P}_{160}\right)_{2}-b-\mathbf{P B N P} \mathbf{P}_{10}\right]-\mathbf{P O} \mathbf{O S S}$. $\mathbf{c}_{3-\mathrm{D}}$ plot of toroidal feature. $\mathbf{f}$ Profile analysis of cyclic polymer marked by the red and blue lines in $(\mathbf{e}) \cdot \mathbf{g}-\mathbf{i}$ TEM images of $c-\left[\mathbf{P B N P}_{10}-\left(b-\mathbf{P T N P} \mathbf{P}_{160}\right)_{2}-b-\mathbf{P B N P}_{10}\right]-\mathbf{P O S S}_{\mathbf{S}} \mathrm{CHCl}_{3}$ at $0.005 \mathrm{mg} \mathrm{mL}^{-1}$ (scale bar: 500,100 , and $5 \mathrm{~nm}$ for $\mathbf{g}$, $\mathbf{h}$, and $\mathbf{i}$, respectively) and the inset in (i) is the diagrammatic sketch of cyclic topology 
For $l$-PBNP $20^{-}\left(b \text {-PTNP }{ }_{160}\right)_{2}$-POSS, however, only solid nanospheres with the average diameter of $30-35 \mathrm{~nm}$ and height of $1 \mathrm{~nm}$ were observed in the AFM images (Supplementary Fig. 51), while there were no any macrorings, indicating that the POSS moiety itself did not bring the linear polymer to form the cyclic topology, just to restrain the intra-chain entanglement of cyclic polymer and expand the single-stranded chains away from the close proximity to each other.

The single cyclic macromolecular topology other than the self-assembly or aggregated morphology was hard to be observed by the transmission electron microscopy (TEM) analysis, and therefore there had been seldom reported to date ${ }^{44}$. As stated, $c$ - $\left[\mathbf{P B N P}_{10^{-}}\left(b-\mathbf{P T N P}_{160}\right)_{2}-b-\mathbf{P B N P}_{10}\right]$ and $c$ - $\left[\mathbf{P B N P}_{10^{-}}\left(b-\mathbf{P N P}_{80}\right)_{2^{-}}\right.$ $b$-PBNP $\left.{ }_{10}\right]$ did not exhibit the macrorings but showed the solid nanosphere morphology in their TEM images with the average diameters of about 25 and $20 \mathrm{~nm}$ (Supplementary Figs. 52 and 53), respectively, because the strong $\pi-\pi$ stacking effect of large aromatic pendants in the two cyclic polymers caused the intra-chain entanglement. Fortunately, the bulky POSS-modified cyclic molecular topology of $c$ - $\left[\mathbf{P B N P}_{10}-\left(b-\mathbf{P T N P}_{160}\right)_{2}-b\right.$-PBNP $\left.\mathbf{P B}_{10}\right]$-POSS was clearly seen from the TEM images with the average outer and inner diameters of $25-35$ and $10-14 \mathrm{~nm}$ at different sample concentrations (Fig. 5g-i and Supplementary Fig. 54), while the TEM images of linear $l$-PBNP ${ }_{20}-\left(b-\mathbf{P T N P}_{160}\right)_{2}$ and $l$-PBNP $\mathbf{P B}_{20}\left(b-\mathbf{P T N P}_{160}\right)_{2^{-}}$ POSS showed only solid nanospheres with the average diameters of about 30 and $35 \mathrm{~nm}$ (Supplementary Figs. 55 and 56), respectively, which were almost consistent with those of AFM analysis. In particular, the POSS moieties connected to the PNBE backbone enabled the polymer chain to expand, and thus the POSS-modified cyclic polymer exhibited a unique concentric macroring molecular topology due to the difference in electron cloud density (Fig. 5i), in which the dark domain represented the POSS moieties with higher electron density and the bright domain was ascribed to the cyclic chains with lower electron density.

\section{Discussion}

We have developed the blocking-cyclization technique, which could be considered as the third strategy and a versatile platform for precisely synthesizing the mono- and multicyclic polymers by successive ROMP of mono- and di-functional NBE derivatives. The cyclic repeat units and ring number could be controlled by simply tuning the loading ratios and adding times of monomers. In cyclic polymers, the $\pi-\pi$ stacking effect of the single-stranded segments generates the intra-chain entanglement junctions, resulting in the $T_{\mathrm{g}}$, photophysical feature, hydrodynamic size, and dielectric loss of each cyclic polymer are apparently different from those of linear counterpart. By virtue of Alder-ene chemistry, the cyclic polymer with unsaturated PNBE backbone was modified by POSS moiety-contained TAD so that the intra-chain entanglement junctions depressed. The cyclic features were fully demonstrated through hydrodynamic volume, $T_{\mathrm{g}}$, UV-vis absorption, fluorescence emission, and dielectric loss; meanwhile, the unique cyclic molecular topology was revealed by AFM and TEM images. Thanks to the well-defined ladderphane structure, which will enable this blocking-cyclization strategy to open a new way and have a potential to cyclic polymers with various backbone and more ring number via commercial Ru-based catalyst and conventional ROMP.

\section{Methods}

Materials. The materials and the synthesis of chemicals are described in Supplementary Methods.

Instrumentation. ${ }^{1} \mathrm{H}(500 \mathrm{MHz})$ and ${ }^{13} \mathrm{C}(125 \mathrm{MHz}) \mathrm{NMR}$ spectra were recorded using tetramethylsilane as an internal standard on a Bruker DPX spectrometer. UV-vis absorption spectra were measured on a UV-1800 spectrometer with the concentration of $0.01 \mathrm{mg} \mathrm{mL}^{-1}$. Fluorescence measurements were performed on an F-7000 spectrofluorometer equipped with a xenon light source (UXL-150S, Ushio) The emission and excitation slit widths were $5 \mathrm{~nm}$ and $5 \mathrm{~nm}$, respectively. The samples were excited at $360 \mathrm{~nm}$ and emission spectra were recorded from 360 to $600 \mathrm{~nm}$. IR spectra were recorded on a Perkin Elmer Spectrum using KBr pellets Gel permeation chromatography (GPC) was used to calculate relative molecular weight and molecular weight distribution equipped with a Waters 1515 Isocratic HPLC pump, a Waters 2414 refractive index detector, and a set of Waters Styragel columns $\left(7.8 \times 300 \mathrm{~mm}, 5 \mathrm{~mm}\right.$ bead size; $10^{3}, 10^{4}$, and $10^{5} \AA$ pore size $)$. GPC measurements were carried out at $40{ }^{\circ} \mathrm{C}$ using THF as the eluent with a flow rate of $1.0 \mathrm{~mL} \mathrm{~min}^{-1}$, and the system was calibrated with polystyrene standard. The intrinsic viscosity and absolute molecular weight of polymers were determined using high-performance size-exclusion chromatography (HPSEC), Viscotek (Viscotek TDAmax) with a differential viscometer (DV), right angle laser-light scattering (RALLS, Viscotek), low-angle laser-light scattering (LALLS, Viscotek), and refractive index (RI) detectors. The column set consisted of a PL $10 \mathrm{~mm}$ guard column $\left(50 \times 7.5 \mathrm{~mm}^{2}\right)$ followed by one Viscotek T6000 column $(8.0 \times 300 \mathrm{~mm}$, $10 \mathrm{~mm}$ bead size; $10^{4} \AA$ pore size $)$ and one Viscotek T4000 column $(8.0 \times 300 \mathrm{~mm}$ $6 \mathrm{~mm}$ bead size; $1.5 \times 10^{3} \AA$ pore size). Matrix-assisted laser desorption ionization time-of-flight mass spectroscopy (MALDI-TOF MS) was performed on a flight mass spectrometer (5800). Mass spectrum was recorded in linear mid-mass positive mode. The matrix, $\alpha$-cyano-4-hydroxycinnamic acid, was dissolved in THF $\left(10 \mathrm{mg} \mathrm{mL}^{-1}\right)$, and the solution was mixed with the polymer solution $\left(50 \mathrm{mg} \mathrm{mL}^{-1}\right.$ in $\mathrm{CHCl}_{3}$ ). The $1.0 \mu \mathrm{L}$ analyte solution was spotted directly onto the thin-layer formed by depositing $1.0 \mu \mathrm{L}$ saturated $\mathrm{NaI}$ cationizing agent in methanol. Thermal gravimetric analysis (TGA) was performed using an SDTA851e/SF/1100 TGA instrument under nitrogen flow at a heating rate of $10^{\circ} \mathrm{C} \mathrm{min}-1$ from 40 to $600{ }^{\circ} \mathrm{C}$. Differential scanning calorimeter (DSC) was performed on a Q2000 DSC system in nitrogen atmosphere. An indium standard was used for temperature and enthalpy calibrations. All the samples were first heated from 40 to $250{ }^{\circ} \mathrm{C}$ and held at this temperature for $3 \mathrm{~min}$ to eliminate the thermal history, and then, they were cooled to room temperature and heat again from 40 to $250^{\circ} \mathrm{C}$ at a heating or cooling rate of $10^{\circ} \mathrm{C} \mathrm{min}-1$. AFM images were taken using a Nanoscope IV Scanning Probe Microscope Controller (Digital Instruments, Veeco Metrology Group) in tapping mode in air at room temperature using silicon tips (spring constant $=40-50 \mathrm{~N} / \mathrm{m}$ resonance frequency $=170-190 \mathrm{kHz}$, and tip radius of curvature $<10 \mathrm{~nm}$ ). The samples were prepared by spin casting dilute solutions $\left(50 \mathrm{ng} \mathrm{mL}^{-1}\right)$ in chloroform onto freshly cleaved mica for the cyclic copolymers. TEM images were recorded on the JEOL2100F microscopes operating at $120 \mathrm{kV}$. Samples for TEM measurement were prepared by depositing a drop of THF solution with a different concentration on the copper grids coated with carbon, followed by air-drying. Additionally, the samples were not stained before measurement because the electron density difference between the two blocks provided sufficient contrast for TEM imaging. The hydrodynamic diameter was determined by means of DLS analysis using a Malvern Zetasizer Nano-ZS light scattering apparatus (Malvern Instruments, UK) with a $\mathrm{He}-\mathrm{Ne}$ laser $(633 \mathrm{~nm}, 4 \mathrm{~mW})$. The Nano ZS instrument incorporates noninvasive backscattering (NIBS) optics with a detection angle of $173^{\circ}$. The $z$-average diameter of the sample was automatically provided by the instrument using cumulate analysis. Dielectric measurements were carried out by a Novocontrol BDS40 dielectric spectrum analyzer over the frequency range of $100 \mathrm{~Hz}$ to $1 \mathrm{MHz}$ at room temperature, and a contacting electrode method was used. The edge side of the guarded electrode is $0.3 \mathrm{~mm}$. The capacitance and the dissipation factor (dielectric loss, or $\tan \delta$ ) of the tested films were recorded.

\section{Data availability}

The authors declare that the data supporting this study are available within the paper and its Supplementary Information File. All other data is available from the authors upon reasonable request.

Received: 23 June 2018 Accepted: 23 November 2018 Published online: 14 December 2018

\section{References}

1. Jacob, F. \& Wollman, E. L. Genetic and physical determinations of chromosomal segments in Escherichia coli. Symp. Soc. Exp. Biol. 12, 75-92 (1958).

2. Bielawski, C. W., Benitez, D. \& Grubbs, R. H. An "endless" route to cyclic polymers. Science 297, 2041-2044 (2002).

3. Bielawski, C. W., Benitez, D. \& Grubbs, R. H. Synthesis of cyclic polybutadiene via ring-opening metathesis polymerization: the importance of removing trace linear contaminants. J. Am. Chem. Soc. 125, 8424-8425 (2003).

4. Laurent, B. A. \& Grayson, S. M. An efficient route to well-defined macrocyclic polymers via "click" cyclization. J. Am. Chem. Soc. 128, 4238-4239 (2006).

5. Schappacher, M. \& Deffieux, A. Synthesis of macrocyclic copolymer brushes and their self-assembly into supramolecular tubes. Science 319, 1512-1515 (2008) 
6. Schappacher, M. \& Deffieux, A. Atomic force microscopy imaging and dilute solution properties of cyclic and linear polystyrene combs. J. Am. Chem. Soc. 130, 14684-14689 (2008).

7. Xia, Y. et al. Ring-expansion metathesis polymerization: catalystdependent polymerization profiles. J. Am. Chem. Soc. 131, 2670-2677 (2009).

8. Shin, E. J. et al. Zwitterionic copolymerization: synthesis of cyclic gradient copolymers. Angew. Chem. Int. Ed. 50, 6388-6391 (2011).

9. Zhang, K., Lackey, M. A., Cui, J. \& Tew, G. N. Gels based on cyclic polymers. J. Am. Chem. Soc. 133, 4140-4148 (2011).

10. Zhang, K., Lackey, M. A., Wu, Y. \& Tew, G. N. Universal cyclic polymer templates. J. Am. Chem. Soc. 133, 6906-6909 (2011)

11. Cai, Y. et al. Cyclic amphiphilic random copolymers bearing azobenzene side chains: facile synthesis and topological effects on self-assembly and photoisomerization. Macromol. Rapid Commun. 35, 901-907 (2014).

12. Laurent, B. A. \& Grayson, S. M. Synthetic approaches for the preparation of cyclic polymers. Chem. Soc. Rev. 38, 2202-2213 (2009).

13. Brown, H. A. \& Waymouth, R. M. Zwitterionic ring-opening polymerization for the synthesis of high molecular weight cyclic polymers. Acc. Chem. Res. 46, 2585-2596 (2013).

14. Hoskins, J. N. \& Grayson, S. M. Synthesis and degradation behavior of cyclic poly( $\varepsilon$-caprolactone). Macromolecules 42, 6406-6413 (2009).

15. Misaka, H. et al. Synthesis of well-defined macrocyclic poly $(\delta$-valerolactone $)$ by "click cyclization". Macromolecules 42, 5091-5096 (2009).

16. Xie, M. et al. Cyclic poly( $\varepsilon$-caprolactone) synthesized by combination of ringopening polymerization with ring-closing metathesis, ring closing enyne metathesis, or "click" reaction. J. Polym. Sci. Part A: Polym. Chem. 47, 3022-3033 (2009).

17. Yang, W. Y., Ahn, J. H., Yoo, Y. S., Oh, N. K. \& Lee, M. Supramolecular barrels from amphiphilic rigid-flexible macrocycles. Nat. Mater. 4, 399-402 (2005).

18. Xu, J., Ye, J. \& Liu, S. Synthesis of well-defined cyclic poly(Nisopropylacrylamide) via click chemistry and its unique thermal phase transition behavior. Macromolecules 40, 9103-9110 (2007).

19. Zhu, W., Li, Z., Zhao, Y. \& Zhang, K. Cyclic polymer with alternating monomer sequence. Macromol. Rapid Commun. 36, 1987-1993 (2015).

20. Ge, Z. et al. High-efficiency preparation of macrocyclic diblock copolymers via selective click reaction in micellar media. J. Am. Chem. Soc. 131, 1628-1629 (2009).

21. Brown, H. A., Chang, Y. A. \& Waymouth, R. M. Zwitterionic polymerization to generate high molecular weight cyclic poly(carbosiloxane)s. J. Am. Chem. Soc. 135, 18738-18741 (2013).

22. Lee, C. U., Smart, T. P., Guo, L., Epps, T. H. \& Zhang, D. Synthesis and characterization of amphiphilic cyclic diblock copolypeptoids from Nheterocyclic carbene-mediated zwitterionic polymerization of $\mathrm{N}$-substituted $\mathrm{N}$-carboxyanhydride. Macromolecules 44, 9574-9585 (2011).

23. Schäler, K. et al. Influence of chain topology on polymer dynamics and crystallization. Investigation of linear and cyclic poly( $\varepsilon$-caprolactone)s by ${ }^{1} \mathrm{H}$ solid-state NMR methods. Macromolecules 44, 2743-2754 (2011)

24. Li, H., Debuigne, A., Jerome, R. \& Lecomte, P. Synthesis of macrocyclic poly (epsilon-caprolactone) by intramolecular cross-linking of unsaturated end groups of chains precyclic by the initiation. Angew. Chem. Int. Ed. 45, 2264-2267 (2006).

25. Kowalski, A., Duda, A. \& Penczek, S. Kinetics and mechanism of cyclic esters polymerization initiated with tin(II) octoate. 3. Polymerization of 1,1-dilactide. Macromolecules 33, 7359-7370 (2000).

26. Kricheldorf, H. R. \& Lee, S. R. Polylactones. 35. Macrocyclic and stereoselective polymerization of beta-D,L-butyrolactone with cyclic dibutyltin initiators. Macromolecules 28, 6718-6725 (1995).

27. Luh, T. Y. Ladderphanes: a new type of duplex polymers. Acc. Chem. Res. 46, 378-389 (2013).

28. Chou, C. M. et al. Polymeric ladderphanes. J. Am. Chem. Soc. 131, 12579-12585 (2009).

29. Yang, H. C. et al. Molecular architecture towards helical double-stranded polymers. Angew. Chem. Int. Ed. 45, 726-730 (2006).

30. Song, W., Han, H., Wu, J. \& Xie, M. Ladder-like polyacetylene with excellent optoelectronic properties and regular architecture. Chem. Commun. 50, 12899-12902 (2014).

31. Chen, J. et al. Double-stranded block copolymer with dual-polarized linker for improving dielectric and electrical energy storage performance. Polymer 127, 259-268 (2017).

32. Chen, J., Li, H., Han, H., Sun, R. \& Xie, M. Multiple polarizations and nanostructure of double-stranded conjugated block copolymer for enhancing dielectric performance. Mater. Lett. 208, 95-97 (2017).
33. Chen, J. et al. Rational design and modification of high- $k$ bis(double-stranded) block copolymer for high electrical energy storage capability. Chem. Mater. 30, 1102-1112 (2018)

34. Lin, W. et al. On the rigidity of polynorbornenes with dipolar pendant groups. Chem. Eur. J. 12, 324-330 (2006)

35. Ke, Y. Z., Lee, S. L., Chen, C. \& Luh, T. Y. Unsymmetrical polymeric ladderphanes by sequential polymerization: a new approach for the template synthesis of polymers with well-defined chain length and narrow polydispersity. Chem. Asian J. 6, 1748-1751 (2011).

36. Choi, T. L. \& Grubbs, R. H. Controlled living ring-opening metathesis polymerization by a fast-initiating ruthenium catalyst. Angew. Chem. Int. Ed. 115, 1785-1788 (2003).

37. Claudino, M., Johansson, M. \& Jonsson, M. Thiol-ene coupling of 1,2disubstituted alkene monomers: the kinetic effect of cis/trans-isomer structures. Eur. Polym. J. 46, 2321-2332 (2010).

38. You, Z., Song, W., Zhang, S., Jin, O. \& Xie, M. Polymeric microstructures and dielectric properties of polynorbornenes with 3,5-bis(trifluoromethyl)biphenyl side groups by ring-opening metathesis polymerization. J. Polym. Sci. Part A: Polym. Chem. 51, 4786-4798 (2013).

39. Zhu, L. et al. Ruthenium-catalyzed cascade metathetical cyclopolymerization of bisnorbornenes with flexible linkers. Macromolecules 46, 656-663 (2013).

40. Love, J. A., Morgan, J. P., Trnka, T. M. \& Grubbs, R. H. A practical and highly active ruthenium-based catalyst that effects the cross metathesis of acrylonitrile. Angew. Chem. Int. Ed. 41, 4035-4037 (2002).

41. Zhao, Y., Chen, J., Zhu, W. \& Zhang, K. Unique post-functionalization method for ROMP polymers based on triazolinedione Alder-ene chemistry. Polymer 74, 16-20 (2015).

42. Xia, Y., Boydston, A. J. \& Grubbs, R. H. Synthesis and direct imaging of ultrahigh molecular weight cyclic brush polymers. Angew. Chem. Int. Ed. 50, 5882-5885 (2011).

43. Boydston, A. J., Holcombe, T. W., Unruh, D. A., Frechet, J. M. \& Grubbs, R $\mathrm{H}$. A direct route to cyclic organic nanostructures via ring-expansion metathesis polymerization of a dendronized macromonomer. J. Am. Chem. Soc. 131, 5388-5389 (2009).

44. Zhang, K., Zha, Y., Peng, B., Chen, Y. \& Tew, G. N. Metallo-supramolecular cyclic polymers. J. Am. Chem. Soc. 135, 15994-15997 (2013).

\section{Acknowledgements}

This research was financially supported by the National Natural Science Foundation of China (Nos. 21871091, 21574041, and 21704025).

\section{Author contributions}

R.S. and M.X. conceived, designed, and directed the project. J.C., H.L. and H.Z. performed the experiments. J.C., H.L., L.Z., X.L. and H.H. analyzed the data. J.C., R.S. and M.X. co-wrote the paper. All the authors discussed the results and commented on the manuscript.

\section{Additional information}

Supplementary Information accompanies this paper at https://doi.org/10.1038/s41467018-07754-1.

Competing interests: The authors declare no competing interests.

Reprints and permission information is available online at http://npg.nature.com/ reprintsandpermissions/

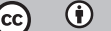

Open Access This article is licensed under a Creative Commons Attribution 4.0 International License, which permits use, sharing, adaptation, distribution and reproduction in any medium or format, as long as you give appropriate credit to the original author(s) and the source, provide a link to the Creative Commons license, and indicate if changes were made. The images or other third party material in this article are included in the article's Creative Commons license, unless indicated otherwise in a credit line to the material. If material is not included in the article's Creative Commons license and your intended use is not permitted by statutory regulation or exceeds the permitted use, you will need to obtain permission directly from the copyright holder. To view a copy of this license, visit http://creativecommons.org/ licenses/by/4.0/.

(C) The Author(s) 2018 